\title{
Craniosynostosis: Forehead Reconstruction Using Sagital Bony Bar (Case Report)
}

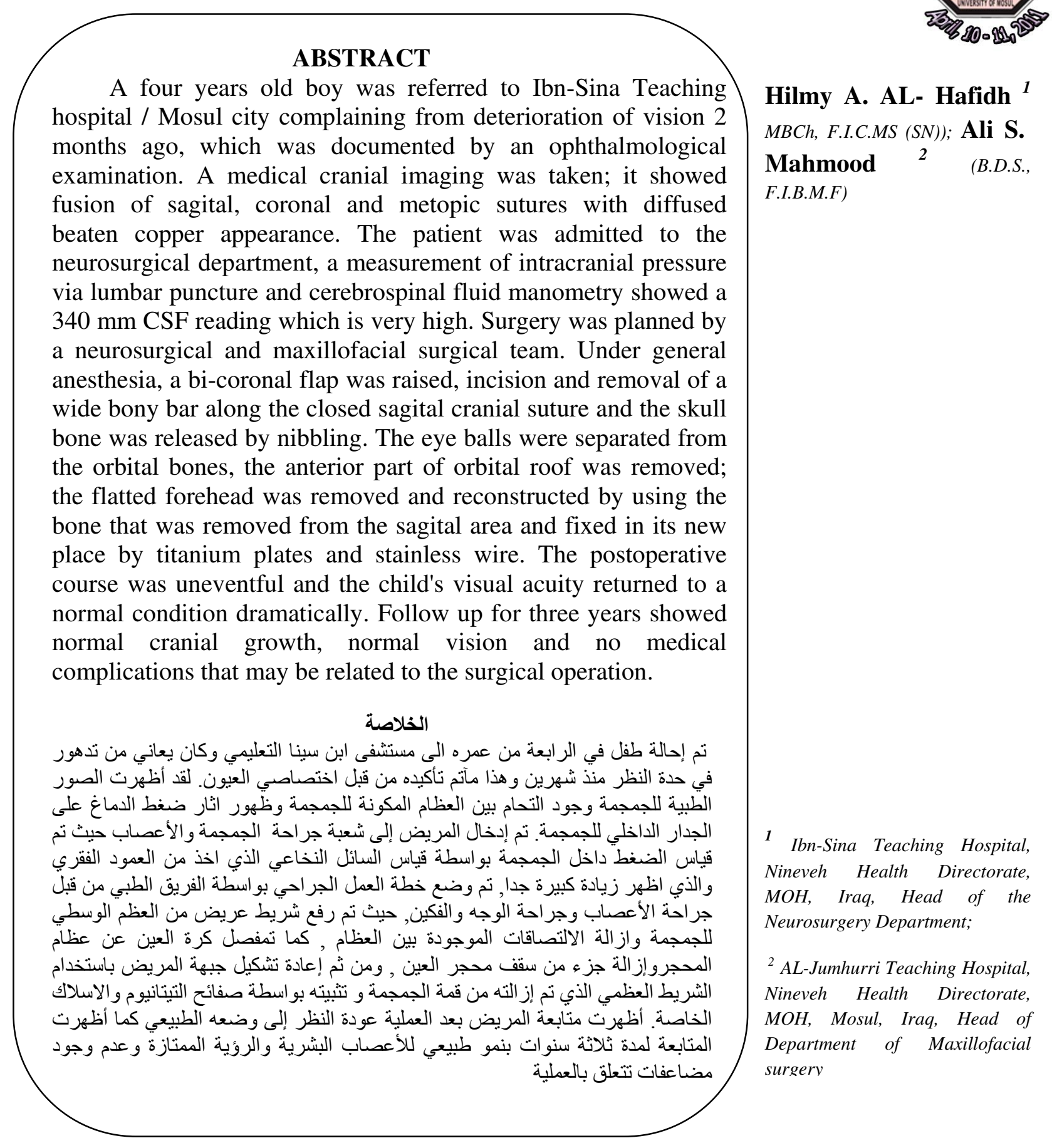

Key Words: Cranial deformity, congenital cranial defect, cranial syndrome. 


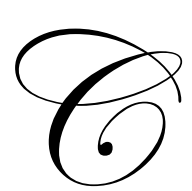

\section{INTRODUCTION}

raniosynostosis, the premature fusion of one or more of the cranial sutures, is the most common human congenital skull defect, with a prevalence of 333-476 per million births ${ }^{(1,2)}$. A single cranial suture involvement is most commonly implicated, while the syndromic craniosynostosis, with a more generalized pattern, is much less common ${ }^{(3)}$. There are over 100 described syndromic synostoses, the most common of which include Pfeiffer, Crouzon, Apert and Saethre-Chotzen ${ }^{(4,5)}$. The majority of patients with craniosynostosis have various skull alterations, which are severe in syndromic type and mainly considered to have arisen from compensatory growth of the skull after stenosis of some sutures and high intracranial pressure ${ }^{(6,7)}$. In cases in which the compensation does not effectively provide enough space for the growing brain, craniosynostosis would result in increased intracranial pressure leading possibly to visual impairment or an impairment of mental development ${ }^{(8)}$.

\section{CASE PRESENTATION}

A four years old boy was referred to Ibn-Sina Teaching Hospital / Mosul city complaining from deterioration of vision 2 months ago, which was documented by a weekly ophthalmological examination; it was reported that there was bilateral proptosis and papilledema in addition to gradual decrease of visual acuity (Figure 1). A skull radiographs, MRI and skull computed tomography (CT) scan were taken; those showed fusion of sagital, coronal and metopic sutures with a diffused beaten copper appearance (Figure 2).

The patient previously seeked treatment in neighboring countries but the surgical team there gave his family $20 \%$ mortality and $80 \%$ possibility of loss of vision during operation; therefore, the family refused doing the operation and returned to treat their boy in Iraq. The patient was admitted to the neurosurgical department in Ibn-Sina Teaching hospital. Measurement of intracranial pressure via lumbar puncture and cerebrospinal fluid monometry was carried out. The intracranial pressure was $340 \mathrm{~mm} \mathrm{CSF}$ which is very high. Surgery was planned by a neurosurgical and maxillofacial surgical team.

Under general anesthesia and endotracheal intubation, a bicoronal incision design was done. Dissection of the scalp was made anteriorly down to the orbital rim and posteriorly to the lambdoid suture, two bur holes on each side of the anterior end of the sagital suture and another two holes were made on each side of the posterior end of the sagital suture; a cut lines with removal of the bony bar including the fused sagital suture was done (Figure 3).

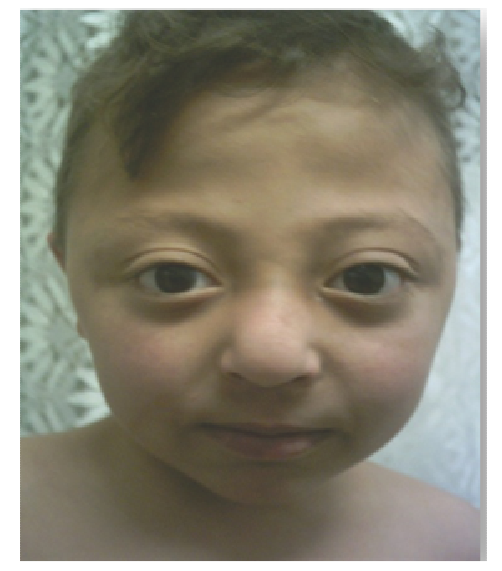

Figure 1

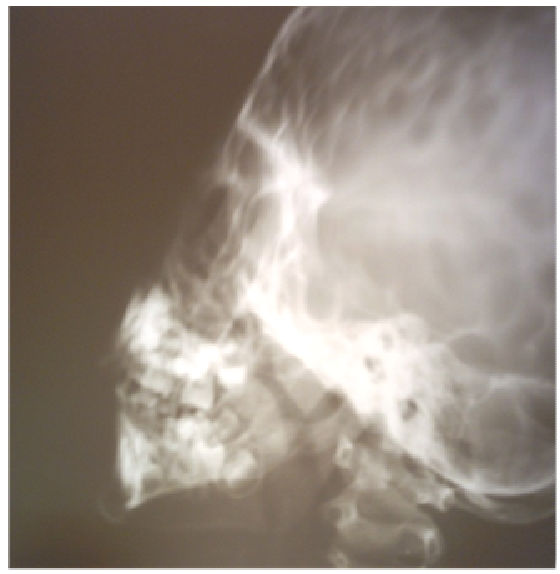

Figure 2

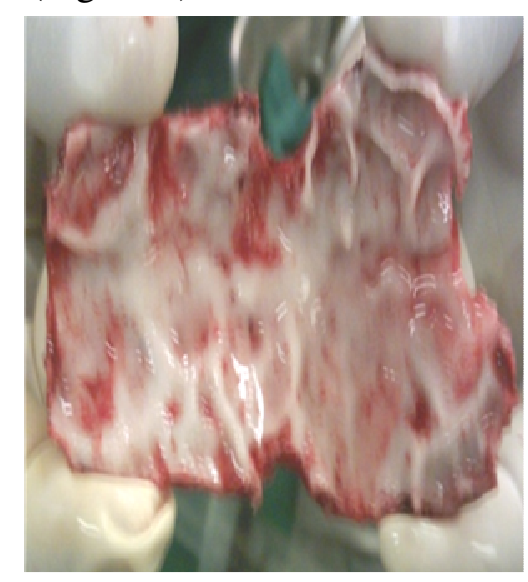

Figure 3

Journal of the $5^{\text {th }}$ Scientific Conference of Dentistry College, Apr. 2011 
Then, the sides of the skull were released by nibbling of bone extending from each bur hole to the base of the skull, so that each parieto-temporal bone on each side becomes free. The eye balls were separated from the orbital margins, the supra orbital bony bar was removed, and then the frontal bone (forehead) which was narrow and flattened was removed. Retraction of the frontal dura with removal of apart (anterior) of the roof of the orbits was done; this gave more space to the orbital cavity. The forehead was reconstructed by application of the bony bar that had been removed earlier from the area of the sagital suture and fixed anteriorly by titanium plates, and posteriorly by stainless steel wires. Eventually, the wound was closed in layers with drain application.

The surgical work took approximately six hours (Figure 4). The postoperative course was uneventful and dependent on ophthalmological examination of the child's visual acuity returning to normal condition dramatically. Follow up for three years with six months recall visits showed normal cranial growth, normal vision and no medical complications that may be related to surgical operation (Figure 5).

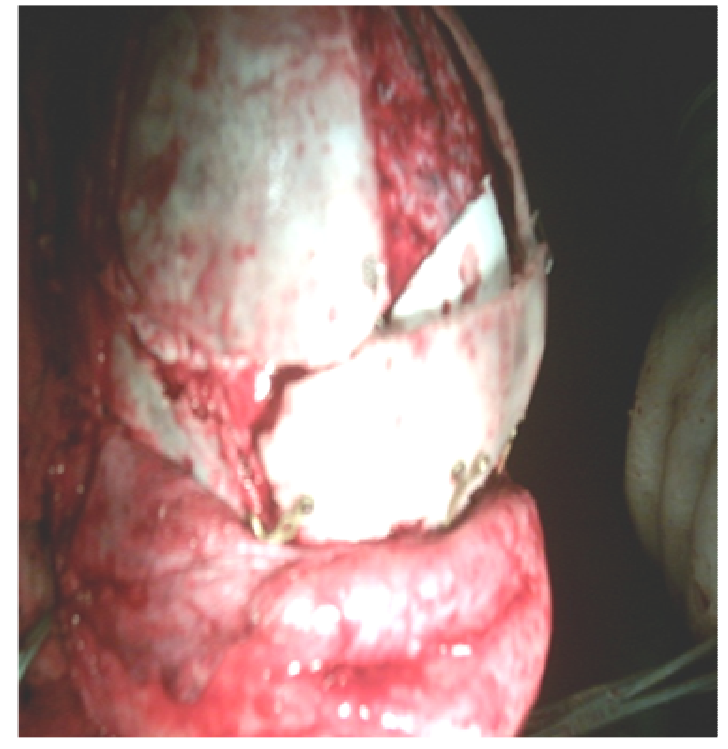

Figure 4

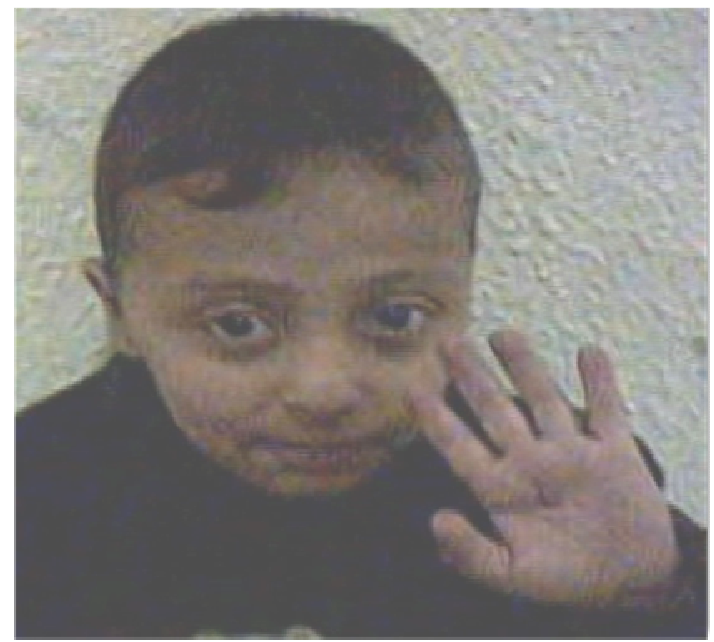

Figure 5

\section{DISCUSSION}

The most common complication in patients with symptomatic craniosynostosisis is elevated intracranial pressure, which is revealed by diffuse, severe beaten copper pattern in radiograph that originates from the brain pressure on cranium ${ }^{(9)}$. Astigmatism in uni-coronal synostosis was previously been reported ${ }^{(10,11)}$ and there was also one previous report of astigmatism in Apert's, Crouzon's, and a mixture of other craniofacial synostoses ${ }^{(12)}$. Although visual loss had been documented in these cases and attributed to secondary optic atrophy (due to chronic papilloedema), amblyopia, exposure keratopathy, or a combination of all three ${ }^{(13,14)}$, there are no studies to demonstrate the degree of visual loss in craniosynostoses. The optimum time for surgical correction of craniosynostosis is during the first year of life, especially the first 
$6^{\text {th }}$ month of age; but in this case the rational for surgery was to improve the visual deficit that was progressively increasing and to prevent the loss of sight.

\section{CONCLUSION}

Insidious craniosynostosis is an unusual cause of chronic papilledema in childhood. The papilledema may be resolved and visual loss can be prevented by surgery; the optimum time for surgical correction of craniosynostosis is during first year of life, especially the first $6^{\text {th }}$ month of age.

\section{REFERENCES}

1. Lajeunie E, Merrer LM, Bonaiti-Pellie C, Marchac D and Renier D. Genetic Study of Syndromic Coronal Craniosynostosis. Am J Med Genet. 1995; 4:55-500.

2. Steinberger D, Reinhartz T, Unsold R and Muller U. FGFR2 Mutation in Clinically Non-Classifiable Autosomal Dominant Craniosynostosis with Pronounced Phenotypic Variation. Am J Med Genet. 1996; 6:66-81.

3. Shin JH, Persing JA. Craniofacial Syndromes in Humans. Neurological Surgery. $5^{\text {th }}$ ed; 2004. Philadelphia: Saunders. P: $3315-3330$.

4. Cohen MM. Craniosynostosis: Diagnosis, Evaluation and Management. New York: Raven. 1996; 33-138.

5. Winter RM, Baraitser M. The London Dysmorphology Database. Oxford: Oxford University Press. 1996; 26-187.

6. Shopfner CE, Jabbour JT, Vallion RM. Craniolacunia. Am J Roentgenol Radium TherNucl Med. 1965; 93:343-349.

7. Wilson WG, Alford BA, Schnatterly PT. Craniolacunia as the Result of Compression and Decompression of the Fetal Skull. Am J Med Genet. 1987; 27:729-730.

8. Gault DT. Renier D, MarchacD and Jones BM. Intracranial Pressure and Intracranial Volume in Children with Craniosynostosis. Plast Reconstr Surg. 1992; 90(3):377-81.

9. Boulay G. The Radiological Evidence of Raised Intracranial Pressure in Children. Br J Radiol.1957; 30:375-377.

10. Denis D, Genitori L, Bolufer A, Lena G., Saracco JB and Choux M. Refractive Error and Ocular Motilityin Plagiocephaly. Child's Nerv Syst. 1994; 16:10-210.

11. Denis D, Genitori L, Conrath J, Lena G. and Choux M. Ocular Findings in Childrenoperated on for Plagiocephaly and Trigonocephaly. Child's Nerv Syst.1996; 9:12-683.

12. Mursch K, Brockmann K, Lang JK, Markakis E and Behnke-Mursch J. Visually Evoked Potentials in 52 Children Requiring Operative Repair of Craniosynostosis. Pediatric Neurosurg. 1998; 3: 29-320.

13. Katzen JT, McCarthy JG. Syndromes Involving Craniosynostosis and Mid-face Hypoplasia. Otolaryngol Clin N Am. 2000; 84: 33-1257.

14. Day S. Normal and Abnormal Visual Development. Paediatric ophthalmology. $2^{\text {nd }}$ ed. 1997. London: Blackwell Science. P: 2-13. 